\title{
Fábrica, sociedade e costumes ${ }^{1}$
}

\author{
Athos F. Soares Maia ${ }^{2}$ \\ Victor Augustus Graciotto Silva ${ }^{3}$
}

\section{Introdução}

A partir do livro "Costumes em comum" de Edward P. Thompson", em especial o capítulo titulado como "Tempo, disciplina de trabalho e capitalismo industrial", podemos abstrair uma reflexão sobre as necessidades humanas condicionadas pelo universo do mercado, onde a fábrica expressou e expressa, ainda hoje, o símbolo maior que, direta ou indiretamente, rege as nossas vidas. O presente trabalho se prende a essas questões, postas por Thompson.

\footnotetext{
Se vamos ter mais tempo de lazer no futuro automatizado, o problema não é "como as pessoas vão conseguir consumir todas essas unidades adicionais de tempo de lazer?", mas "que capacidade para a experiência terão as pessoas com esse tempo livre?"'[...]como preencher os interstícios de seu dia com relaçōes sociais e pessoais mais enriquecedoras e descompromissadas; como derrubar mais uma vez as barreiras entre o trabalho e a vida. (THOMPSON, 1998, p. 302)
}

Diante da relação entre a sociedade e o que é possível pensar sobre a palavra fábrica, o nosso objetivo primeiro estava em aprofundar as leituras sobre o tema com a intenção de compreender a fábrica em alguns de seus significados, priorizando o século XVIII enquanto o período em que é possível analisar seu surgimento, em termos institucionais.

Para tanto, a primeira leitura feita refere-se à obra de Eric J. Hobsbawm, "A Era das Revoluções", cuja análise permite uma visão ampla do processo conhecido como Revolução Industrial, abrangendo tanto seu surgimento e seu impacto na Inglaterra no século XVIII, quanto o seu significado em relação às modificações que ela trouxe no universo do trabalho.

Além disso, o texto de Thompson, citado à cima, proporcionou uma análise centrada na fábrica e nas modificações dos hábitos dos trabalhadores -

\footnotetext{
'O presente artigo foi realizado a partir do trabalho de graduaçăo apresentado à disciplina História Moderna II do Curso de História do Setor de Ciências Humanas, Letras e Artes da Universidade Federal do Paraná, tendo como professora a Dra. Ana Paula Vosne Martins.

${ }^{2}$ Graduação - História/UFPR.

${ }^{3}$ Graduação - História/UFPR.

${ }^{4}$ THOMPSON, 1998.

${ }^{5}$ HOBSBAWM, 1982. 
que estavam inseridos nessa nova rotina de trabalho. A imposição de uma nova disciplina de trabalho, além de confrontar velhos costumes, condicionou os trabalhadores a uma nova noção de tempo, que por sua vez traçava os limites espaciais e temporais entre o lazer e o trabalho, estabelecendo uma relação de distanciamento entre o tempo ocioso e o tempo útil.

Buscando compreender o significado da fábrica, no momento em que surge, como um local dotado de uma intenção particular - de reunir pessoas com certos saberes para a produção de mercadorias, inseridas em uma lógica de mercado onde a classe burguesa era a protagonista - acatamos o texto "O Nascimento das Fábricas" de Edgar Salvadori de Decca ${ }^{6}$. Conduzindo suas reflexőes nesse sentido, ele aponta o século XVIII como o momento no qual a fábrica assume um papel que iria condicionar toda a sociedade nos séculos seguintes.

Porém, tais leituras não supriram nosso anseio de tentar responder em tons reflexivos "como derrubar mais uma vez as barreiras entre o trabalho e a vida"”. Contribuir para essa discussão foi o que nos motivou a realizar tal trabalho, entretanto sentíamos necessidade de ir além da compreensão da instituição fabril durante o século XVIII.

Ao estarmos envolvidos nessa problemática, em um certo momento percebemos que algumas palavras que centravam as leituras feitas - introjeção do tempo, disciplina, princípio normativo da sociedade - nos lembravam textos do sociólogo Norbert Elias.

Ao analisar duas de suas obras, "O Processo Civilizador" ${ }^{8}$ e "Envolvimento e Alienação", , construímos a proposta final do nosso trabalho, que consiste em tentar estabelecer uma perspectiva de análise sobre a fábrica no século XVIII, através de um olhar fundamentado nas idéias presentes nos conceitos teóricos de Elias.

O mérito desse trabalho, ao nosso ver, está no modo pelo qual ele surgiu e se desenvolveu. Dando os devidos créditos ao trabalho final, o mais enriquecedor foram as discussões que nos levaram a construir uma tentativa de diálogo entre certos conceitos teóricos de Norbert Elias, com as reflexões sobre a fábrica no século XVIII dos demais autores citados.

\footnotetext{
${ }^{6}$ DECCA, 1984.

${ }^{7}$ THOMPSON, 1998 , p. 302.

${ }^{8}$ ELIAS, 1993.

${ }^{9}$ ELIAS, 1998.
} 


\section{Considerações gerais sobre o caso inglês}

Para entendermos a fábrica na Inglaterra do século XVIII, é preciso primeiro que situemos a condição em que o país se encontrava durante este período.

A Inglaterra não possuía nenhum tipo de superioridade tecnológica ou cientifica em relação a outros países da Europa como a França ou a Alemanha. Tanto no campo das Ciências Naturais quanto no das Exatas a superioridade francesa era incontestável. E até mesmo na economia os contabilistas e fisiocratas franceses como Quesnay, Turgot e Lavoisier tinham maior projeção do que os formados pela escola britânica. Os franceses e alemães possuíam escolas técnicas muito antes que os ingleses pensassem em construí-las. A educação na Inglaterra era medíocre; as escolas públicas possuíam um ensino "horrível" e Oxford e Cambridge eram "intelectualmente nulas". ${ }^{10}$ As escolas e universidades escocesas tinham melhor reputação que as inglesas, o que levava a aristocracia inglesa a preferir educar ali seus filhos.

Portanto era natural que as suas inovações técnicas fossem bastante simples, e que não estivessem além da capacidade de construção dos carpinteiros, moleiros e serralheiros da época. A lançadeira, o tear e a fiadeira automática eram máquinas simples de manejar e não exigiam muitos conhecimentos técnicos daquele que as operava.

Indo direto ao ponto, o que possibilitou a Inglaterra a se tornar uma nação a dar início à expansão fabril antes dos seus vizinhos europeus foi sua relativa estabilidade interna. Naquele país o lucro privado e o desenvolvimento econômico tinham se estabelecido como objetivos principais da política governamental. A política já estava ligada ao lucro, e o dinheiro passava a influenciar as decisões de estado.

A produção agrícola aumentara a ponto de já poder abastecer a população urbana. Havia também um excedente populacional apto a ser "utilizado" nas fábricas, suprindo assim a necessidade de mão-de-obra farta e barata.

Por fim, um volume considerável de capital estava sendo aplicado na melhoria das estradas e portos, juntamente com investimentos na construção de navios para dinamizar a frota mercante.

Entretanto, apesar de todas essas considerações, é importante analisarmos o impacto que tais modificações causaram na vida dos trabalhadores pobres. Como uma rotina de trabalho anterior ao advento da fábrica se adaptou a todas as modificações que ela trouxe? Como os velhos costumes reagiram à nova dinâmica de trabalho? Qual a dimensão

${ }^{10}$ HOBSBAWM, 1982, p. 46. 
do impacto que os trabalhadores sofreram com a reestruturação de perspectiva de tempo que regia suas vidas? Como, enfim, se transformaram os hábitos de todo um segmento social devido a interesses econômicos que, mais tarde, vieram a dar início ao que ficou conhecido depois como Revolução Industrial?

\section{O valor do Tempo}

Antes que o relógio impusesse um novo ritmo de trabalho as pessoas possuíam uma relação bem diferente com o tempo. Quando, nas pequenas comunidades de agricultores, as tarefas como plantio, construção de casas e cuidados com os animais ditavam o ritmo do trabalho, as pessoas não se preocupavam com o passar das horas e dos minutos. Realizavam suas tarefas até que estivessem completas. O trabalhador cuidava daquilo que era uma necessidade, parecendo haver pouca diferença entre o "trabalho e a vida"- a duração da tarefa executada é que determinaria o tempo de trabalho de cada um.'

Entretanto, o tempo adquiriu feições diferentes a partir do momento em que passa a haver a contratação de mão-de-obra. O tempo, a partir daí, passa a assumir valor econômico. Passa a haver então, uma diferença entre o tempo do empregador e o tempo do trabalhador.

Thompson nos diz isso de forma muito clara:

Aqueles que são contratados experenciam uma distinção entre o tempo do empregador e o seu "próprio" tempo. E o empregador deve usar o tempo de sua mão-de-obra e cuidar para que não seja desperdiçado: o que predomina não é a tarefa, mas o valor do tempo quando reduzido a dinheiro. O tempo é agora moeda: ninguém passa o tempo, e sim o gasta.(THOMPSON, 1998, p. 272)

Portanto, a partir do momento em que se estabelece a diferença do tempo através de uma relação hierárquica entre o patrão e o trabalhador, o tempo de trabalho passa a adquirir um valor de mercadoria, sendo este um dos fatores que vai determinar o montante do salário a ser pago pelo empregador.

É neste contexto que o relógio passa a ganhar importância; é necessário que se tenha um controle mais rigoroso do tempo visto que os novos ritmos de trabalho passam a ser demarcados por ele.

O relógio se populariza no século XVIII, quando se torna artigo de conveniência, ou seja, quando tanto ricos como pobres poderiam possuir um. Estimativas revelam que havia mais de 2.000 .000 de relógios

$"$ THOMPSON, 1998, p. 271. 
só na Inglaterra. ${ }^{12}$ Mas independente do fato das estimativas serem verdadeiras ou não, seu valor está naquilo que elas não dizem com clareza, ou seja, a mudança no comportamento da classe trabalhadora, que aceita, aos poucos, uma nova concepção de tempo. Tempo este que foi objeto de manipulação pelos patrões, impositores de um ritmo de trabalho que transparece uma única conveniência: o lucro.

Mas antes que a nova disciplina de trabalho, imposta pela fábrica, tivesse êxito em toda a sociedade, o comportamento dos trabalhadores pobres era bem diferente. Principalmente entre aqueles autônomos, como artesãos, sapateiros, tecelões e outros. Costumavam alternar períodos trabalho intenso com períodos de grande ociosidade. Havia entre eles o costume, juntamente com os mineiros de carvão, tipógrafos, cuteleiros, oleiros e vários outros, de não trabalharem na Segunda-feira. A Santa Segunda-Feira, como era conhecida, era um dia de descanso e confraternização com os amigos, um dia para fazer compras e cuidar dos interesses pessoais. Devido à associação deste dia a bebedeiras, ele começa a ser alvo de perseguições. Afinal, incitava o trabalhador ao ócio, levando-o para o caminho da extravagância e da libertinagem.

Olhando cuidadosamente para esse comportamento dos trabalhadores, o que percebemos não é nada menos que o próprio ritmo de trabalho irregular que eles cultivavam há muito tempo. Era através dessa tensão entre dias de trabalho árduo e dias de ócio que eles viviam a vida. Não havia a necessidade de "sincronização do trabalho", "de subdivisão dos processos de produção", a roda do tempo girava mais devagar. ${ }^{13}$

\section{A transição para o sistema de trabalho industrial}

Esse é um momento de profundo conflito na sociedade inglesa, pois além de ser um período em que passa a haver sincronização do trabalho e "melhor aproveitamento" do tempo de serviço, há também uma maior perseguição aos costumes dos trabalhadores operários. A ociosidade passa a ser crime punível com multas; o tempo torna-se propriedade exclusiva de quem contrata o serviço e a forma com que os donos de fábrica se utilizavam dele revela seu desejo de acabar com os velhos costumes dos trabalhadores pobres, como meio de formar uma nova classe de trabalhadores. Ataques mais violentos aos costumes, esportes e feriados populares eram devolvidos com violência similar. Greves bem sucedidas conseguiam diminuir o tempo de serviço dentro das fábricas e melhorarem a condição de vida do trabalhador. Patrões que

\footnotetext{
${ }^{12}$ Ibid., p. 278-279.

${ }^{13}$ Ibid., p. 280. 
antes manipulavam o tempo, forçando seus trabalhadores a uma jornada de trabalho maior - um supervisor, o único que podia carregar um relógios dentro da fábrica, adiantava ou atrasava as horas segundo seus interesses - tiveram que mudar de postura a partir do momento em que os funcionários se organizaram e passaram a reivindicar os seus direitos.

Entretanto, é preciso ressaltar que as condições de vida na época não eram boas. Um trabalhador que ficasse desempregado corria o risco de se tornar um alcoólatra. $\mathrm{O}$ medo de que uma máquina pudesse roubar o emprego de um homem, fazia com se instalasse um ambiente de tensão nas fábricas. Nos momentos de maior descontentamento e raiva, os empregados invadiam as fábricas para destruir os equipamentos que os ameaçavam. Tinham o apoio de vários outros segmentos da sociedade, também não beneficiados pela expansão industria; fazendeiros, pequenos negociantes e parte da imprensa apoiavam as lutas por melhores condições de vida. O grau de desamparo em que vivia a população nessa época é atestado pelas péssimas condições de moradia e a baixa expectativa de vida. A bebida, a prostituição, o infanticídio e o aumento da taxa de criminalidade expressam de forma bem clara o sentimento da população naquele instante de plena ebulição da Revolução Industrial. ${ }^{14}$

Por fim, apesar de todas as resistências, surgiram novos hábitos de trabalho e a nova disciplina de tempo conseguiu se solidificar. Supervisão e divisão do trabalho, multas, incentivos em dinheiro e outras formas de aliciar o trabalhador conseguiram mudar o seu comportamento, ainda que isso tenha levado algumas gerações para consumar-se. O que reforça o quanto foi árduo o processo de transição de uma sociedade préindustrial para outra, industrial de fato; processo este que implicou em uma remodelação dos costumes e da concepção do trabalho-tempo-lazer em toda uma sociedade.

\section{Tempo e trabalho, envolvimento e alienação}

O presente tópico não é nada mais do que um simples exercício analítico que tem por finalidade aproximar os trabalhos de Thompson e Norbert Elias. A finalidade é tentar achar aspectos em comum entre as duas obras que possam nos ajudar a entender melhor ambas e que possam contribuir no estudo desse trabalho. Antes é melhor que se faça uma apresentação antecipada dos conceitos de Norbert Elias para que se possa facilitar melhor nossa tarefa.

Em seu livro Envolvimento e Alienação a preocupação central do autor é com a capacidade do homem em criar conhecimento. Afirma que o

${ }^{14}$ HOBSBAWM, 1982, p. 225.

Reviritu Yermericule 
homem é um animal que vive em comunidade com outros homens, portanto tem uma bagagem cultural com a qual compartilha com outras pessoas, o que significa que todo conhecimento que ele adquiriu inicialmente foi passado pelo grupo ao qual faz parte, portanto o homem não recebeu nenhum conhecimento direto da natureza. Todo o conhecimento que ele vier a ganhar por si só terá implícito filtro da cultura onde foi criado. Por isso todo conhecimento do homem está diretamente ligado a características da cultura onde foi criado.

A outra questão inerente a esse processo é o grau de envolvimento, de proximidade do indivíduo com as questões que vêm a ser tratadas como um objeto de pesquisa. Quanto mais envolvido ele está em uma questão, mais ele perde a capacidade de criticá-la, analisá-la. Portanto, há um grau de alienação necessário para que se possa interpretar questões de forma correta e ponderada. ${ }^{15}$ Uma espécie de distanciamento que o homem tomaria para refletir sobre qualquer assunto que seja do seu interesse. O envolvimento - principalmente aquele de um indivíduo com a sociedade da qual ele faz parte - é mais paixão do que razão.

Esses dois conceitos não se aplicam a nenhum período específico da história, podendo ser usados por qualquer um. ${ }^{16} \mathrm{O}$ que interessa é entender como o homem fazia uso de cada um desses atributos em diferentes situações e contextos históricos.

A questão chave é: como os moralistas liberais se viam em contraposição aos trabalhadores pobres do século XVIII? Thompson procura responder à questão fornecendo-nos algumas pistas.

É obvio que nenhum daqueles homens falava acerca de si mesmo em seus textos, mas a quantidade de citações que faziam a respeito de trabalhadores pobres que economizavam e ficavam ricos depois, é impressionante. As citações sobre morte, inferno e paraíso também aparecem com freqüência e estão ligadas ao mau aproveitamento do tempo e à idéia de ociosidade. $\mathrm{Na}$ maioria dos casos os autores desses escritos se colocavam como a voz da consciência moral em defesa dos valores cristãos.

Eram pessoas "de bem"; provavelmente todos tinham uma boa condição social que lhes permitia ter uma vida sem privações ou insegurança. É obvio que o grau de envolvimento com que tratavam a questão dava a esta última um ar quase santo. De qualquer forma, a maneira como os moralistas se empenhavam em combater os antigos hábitos da população pobre lhes proporcionou bastante destaque na

\footnotetext{
${ }^{15}$ ELIAS, 1998 , p. 45.

${ }^{16}$ Ibid, p. 31.
} 
sociedade da época. Não há a menor sombra de dúvida de que o comportamento que tinham era completamente envolvido, tratava-se de um grupo de pessoas compromissadas com a salvação da alma do homem, e não de sua carne, e eles fariam tudo para conseguí-lo.

É preciso fazer uma ressalva, voltando a Norbert Elias, para entendermos que nem todo envolvimento é prejudicial ao homem. Conforme este mesmo autor afirma, em alguns casos, como os do fanatismo religioso ou do patriotismo extremado, o envolvimento é necessário para que o indivíduo possa levar uma vida feliz ou pelo menos, com alguma auto-estima. Talvez, sob o prisma da época, os moralistas fossem vistos como homens altruístas tentando recuperar pessoas sem fé e desiludidas.

O fato de apresentarem um comportamento envolvido não impede que se questione o real significado daquilo que escreviam. Poderia ser só engodo. A fé seria então só um meio de justificação de uma forte pressão social; os trabalhadores sendo obrigados a modificar seus costumes não em prol da religião, mas de interesses econômicos pertinentes ao Estado. Ou melhor, talvez possa ser um erro de enfoque tentar usar categorias tenuamente definidas como Envolvimento e Alienação, para se pensar um contex to tão conturbado como foi o século XVIII na Inglaterra. É difícil tentar falar de alienação nesse cenário tão difícil, talvez isso seja possível apenas para os estudiosos que podem fazer esse exercício de análise, tentando minimizar, o máximo possível, os riscos de cair em incoerência. Esperamos estar dentro desse grupo.

\section{O nascimento da Fábrica e a continuidade do Processo Civilizador}

Em tons gerais, Edgar de Decca centra seu texto primeiramente no significado da palavra trabalho, que apresenta teor negativo até um certo período. Em torno do século XVIII, ela viria a assumir um teor positivo. Essa transformação responde à visão do universo burguês, onde a fábrica é tida como o símbolo da utopia burguesa que transformou a sociedade, condicionando todos a olhar para o trabalho com bons olhos.

Tal processo de mudança da concepção do significado da palavra trabalho pode ser percebida através de alguns pensadores entre o século XVII e XIX: Locke coloca o trabalho como fonte de toda a propriedade; para Adam Smith que era fonte de toda a riqueza; e para Marx a fonte de toda a produtividade e expressão da própria humanidade do indivíduo.

Entretanto, a mudança do significado da palavra trabalho assume um outro teor quando observada no interior de seus protagonistas: os trabalhadores. 
Aqueles primeiros homens, que se viram constrangidos pela pregação moral do tempo útil e do trabalho edificante, sentiram em todos os momentos de sua vida cotidiana o poder destrutivo desse novo princípio normativo da sociedade. (DECCA, 1984, p. 9)

Uma imposição de valores, um poder destrutivo que possibilita definir a fábrica a partir de sua intenção de organizar e disciplinar o trabalho; situação em que o tempo é introjetado no trabalhador de modo a constituir um comportamento específico, de controle e rigidez, inspirados nas máquinas.

Essa mudança de comportamento assume papel preponderante na análise de Decca sobre o sistema de fábricas.

\begin{abstract}
Enfim, as relaçôes sociais, produzidas a partir da expansão do mercado capitalista - e o sistema de fábrica é seu "estágio superior" -, tornaram possível o desenvolvimento de uma determinada tecnologia, isto é, aquela que supõe a priori a expropriação dos saberes daqueles que participam do processo de trabalho. Nesse sentido, foi no sistema de fábrica que uma dada tecnologia pode se impor, não apenas como instrumento para incrementar a produtividade do trabalho, mas, muito principalmente, como instrumento para controlar, disciplinar e hierarquizar esse processo de trabalho. (DECCA, 1984, p. 40)
\end{abstract}

Conforme Norbert Elias, as formações sociais não surgem nem de modo racional, nem irracional, mas sim das mudanças nas formas de conduta $\mathrm{e}$ de sentimento dos indivíduos. Tais mudanças estão relacionadas com funções sociais mais diferenciadas, que atuam de modo a regular e ditar o ritmo dessas mudanças individuais. Controle e autocontrole, auto-limitação, interiorização de sentimentos, são alguns dos elementos que Norbert Elias analisa para mostrar as mudanças de comportamento da sociedade guerreira medieval para a sociedade de corte.

A fábrica, ao nosso ver, insere-se nesse modelo teórico. A aprendizagem do controle e autocontrole que geram interiorização de sentimentos como vergonha e repugnância, fato que ocorre devido ao processo de observação mútua dos grupos sociais, assume no universo da fábrica setecentista imensas proporções. Isto é, a fábrica pode ser pensada como um grupo de função mais diferenciada que imprime uma mudança de comportamentos, como por exemplo no que diz respeito à noção de tempo trabalhada em tópico anterior, que culmina em exercer um monopólio de poder por sobre toda a sociedade.

\title{
Conclusão
}

Travar um diálogo entre certos conceitos de Norbert Elias e o significado da fábrica no século XVIII mostrou-se uma tarefa árdua, no sentido da complexidade para articular e expressar as reflexões na forma escrita desse trabalho. 
Porém, uma reflexão final merece ser arriscada. Norbert Elias nos fala que o "processo civilizador" se constitui em uma espiral: interdependências entre formações sociais, umas mais diferenciadas que as outras; tensão entre os comportamentos e normas de tais grupos; constatação de uma mudança; e o predomínio de um centro de poder na sociedade que exerce um monopólio. Tem-se uma dinâmica das interdependências, um movimento de lutas competitivas isentas de monopólio que geram um monopólio, que por sua vez irá gerar outra vez um movimento de lutas competitivas isentas de monopólio, e assim por diante. Um jogo constante de equilíbrio e desequilíbrio, isto é, um predomínio de tensões sociais, políticas e econômicas.

Pensamos a fábrica a partir desse modelo, como um dos grupos que se insere num movimento de lutas isentas de monopólio, isto é, nas interdependências entre as formações sociais. Esse momento se localiza entre os séculos XVII e XVIII, quando a fábrica encontra-se em processo de consolidação e caracteriza um grupo com função mais diferenciada. $\mathrm{O}$ processo de tensão pode ser observado durante o século XVIII, principalmente a respeito da mudança da noção do trabalho que implicou em novas disciplinas e costumes que estavam sendo impostos no interior da fábrica e fora dela. As mudanças decorrentes no ritmo de vida dos trabalhadores consolidam-se e tornam-se um padrão social do indivíduo e da sociedade no século XIX. Enfim, a partir do século XIX estendendo-se aos dias de hoje, a fábrica assume o signo de um sistema econômico e político que exerce um monopólio de poder em pelo menos todo o Ocidente.

Retomando a questão que nos levou a realizar esse trabalho, através da qual Thompson busca refletir sobre a possibilidade de uma mudança nesse ritmo predominante da sociedade, onde o trabalho é o cerne e a razão de existência da sociedade e do indivíduo, temos que tal utopia posta por ele de uma sociedade com capacidade de usufruir de outras experiências não relacionadas ao universo de trabalho, mostra-se como uma possibilidade. Achamos que é possível "separar a vida do trabalho", entretanto consideramos que o trabalho está preso a esse sistema que vigora hoje, o capitalismo ou sua expressão mais conhecida em tons políticos, o neoliberalismo, que tem na fábrica a sua expressão essencial.

A fábrica exerce atualmente um monopólio de poder. Ela significa tanto o pilar econômico do capitalismo, como político do neoliberalismo. Significa o lucro e o prejuízo, a reprodução de um sistema excludente e explorador, reproduz e sobrevive da desigualdade social.

Pensar em uma vida não mais presa a esses valores, significa pensar em um sistema onde a instituição fabril e todos os seus desdobramentos não mais exerçam um monopólio de poder. Significa pensar em dar vazão ao processo civilizador, em sua continuidade, nessa espiral que se move criando e 
recriando outras formações sociais e funções sociais mais diferenciadas, que irão culminar em exercer um monopólio de poder, como a fábrica ainda exerce.

Temos um pensamento otimista, acreditamos que está ocorrendo um movimento de lutas isentas de monopólio que por fim poderá instaurar um novo, que não seja a fábrica. Entretanto, isso significa pensar em um outro sistema político e econômico, que não é nem o presente capitalismo nem o dito derrotado socialismo.

Pensamos em um sistema onde não caiba a desigualdade social, meio único ao nosso ver para possibilitar a liberdade do indivíduo perante as grades que o trabalho impôs. Temos pensadores que caminham nesse sentido. Temos organizações não governamentais que optam por não terem vínculo com o Estado, e nem com os ditos "fins lucrativos", que trabalham em prol de lutas que defendem uma cidadania igualitária e não excludente.

Enfim, ao mesmo tempo que não temos uma alternativa em tons macros, isto é, não temos alternativas de sistemas políticos e econômicos, temos a reflexão e a ação de pessoas e de grupos com o intuito de construir, então, uma alternativa. A nossa expectativa é expressar e contribuir para esse movimento. Está aí o nosso trabalho.

\section{Referência bibliográfica}

DECCA, Edgar Salvadori de. O Nascimento das Fábricas. 2. ed. São Paulo : Brasiliense, 1984, p. 6-40.

ELIAS, Norbert. O Processo Civilizador. Rio de Janeiro, Jorge Zahar Editor, 1993. v. 2: Formação do Estado e Civilização.

. Envolvimento e Alienação. Rio de Janeiro : Bertrand Brasil, 1998.

HOBSBAWN, Eric J. A Era das Revoluções: Europa 1789-1848. 4 ed. Rio de Janeiro: Paz e Terra, 1982.

THOMPSON, Edward P. Costumes em comum. São Paulo : Companhia das Letras, 1998, cap. 6: Tempo, disciplina de trabalho e capitalismo industrial. 